\title{
The Influence of Microstructure and Lattice Strain on Tetragonality Factor and Dielectric Properties of Ferroelectric Ceramics $\mathrm{BaTiO}_{3}$
}

\author{
M.J. Chrunik ${ }^{a, *}$, S. KŁosowicz ${ }^{a}$, P. Perkowski ${ }^{a}$, M. Mrukiewicz $^{a}$, P. Morawiak ${ }^{a}$ \\ AND D. ZASADA ${ }^{b}$
}

${ }^{a}$ Institute of Applied Physics, Military University of Technology, Gen. S. Kaliskiego 2, 00-908 Warsaw, Poland ${ }^{b}$ Department of Advanced Materials and Technologies, Military University of Technology Gen. S. Kaliskiego 2, 00-908 Warsaw, Poland

\begin{abstract}
This work is devoted to direct process of molten salt synthesis and studies on barium titanate $\left(\mathrm{BaTiO}_{3}, \mathrm{BT}\right)$, belonging to ferroelectric crystal group type perovskite $\mathrm{BO}_{3}$. This material thanks to its noncentrosymmetric, fully tetragonal structure possesses at room temperature (up to $T_{\mathrm{c}}=135^{\circ} \mathrm{C}$ ) the spontaneous polarization. Due to this fact BT can be applied as piezoelectric material in electromechanical transducers, so as an excellent dielectric in multilayer capacitors and many other devices. With grain size reduction of BT ceramics to nanometric level it leads to permanent transformation into paraelectric state with minimized energy and to lose its specific features as a consequence, even at room temperature. In case of structural agent, means as tetragonality factor, it has a crucial influence on investigated material properties and it is referred in current paper. It is a row of complementary researching methods allows to confirm the presence of desired tetragonal BT phase in nano or micropowders obtained by means of molten salt synthesis route. For different temperature variants of synthesis X-ray diffraction analysis were undertaken and precise unit cells parameters both with tetragonality factor were determined using the Cohen method. Based on structural studies the lattice strains and crystallite sizes were estimated through the Williamson-Hall method. Using scanning electron microscopy the powders morphology and grain size distribution were done. Dielectric measurements of sintered BT ceramics were carried out to determine the Curie temperatures, dielectric permittivities and loss factors in prepared capacitors.
\end{abstract}

DOI: $10.12693 /$ APhysPolA.124.1034

PACS: 77.80.B-, 77.80.bj, 77.80.bn

\section{Introduction}

Barium titanate $\left(\mathrm{BaTiO}_{3}, \mathrm{BT}\right)$ is one of the first developed (1942) piezoelectric ceramics, used to fabricate electromechanical transducers. It belongs to perovskites type ${ }^{\mathrm{II}} \mathrm{B}^{\mathrm{IV}} \mathrm{O}_{3}$. At room temperature $\mathrm{BT}$ occurs in ferroelectric state and can reach high dielectric constant value (up 10000). Moreover, it is characteristic with low Curie temperature $\left(T_{\mathrm{c}}=135^{\circ} \mathrm{C}\right)$ and relatively low electromechanical coupling coefficient $(k=0.38)$. Opposed to $\mathrm{PbTiO}_{3}$ or $\mathrm{Pb}\left(\mathrm{Zr}_{x} \mathrm{Ti}_{1-x}\right) \mathrm{O}_{3}$ (PT and $\mathrm{PZT}$, respectively) it is not toxic [1]. Besides it, BT has unique optical properties. It is able to work in UV-VIS range and can be applied as a photorefractive crystal. From all well-known inorganic crystals it has one of the highest electrooptical coefficients. In optoelectronics BT is applied as nonlinear (NLO) crystal [2].

Both efficient and fast method in obtaining polycrystalline BT is molten salt synthesis (MSS) [3, 4]. This technique eliminates inconveniences accompanied to conventional technologies. The oldest industrial method [4] in fabricating $\mathrm{BT}$ powders based on high-temperature

\footnotetext{
*corresponding author; e-mail: mchrunik@wat.edu.pl
}

calcination. In the last decade a microwave-assisted solid state reaction was elaborated [5], reducing processing time at the cost of higher temperatures. Chemical routes of BT synthesis include the technologically different ways, for instance sol-gel, coprecipitation and hydrothermal processes. All of them based on multi-staged and time-consuming synthesis. Their main disadvantage is insolubility of titanium oxide in conventional solvents [6].

Tetragonal BT monocrystals can be successfully obtained via growth from flux, described by Remeika et al. [7]. The BT single crystal growth from stoichiometric melt is incommensurably difficult in comparison with other crystals [8] grown from flux. Both bulk crystals and polycrystalline BT ceramics have their applications in industrial and technology due to their specific features, mainly for noncentrosymmetric structure.

Through the last two decades it was proved that for polycrystalline BT the grain size has a significant influence on its structure [9]. The coarse BT ceramics are fully tetragonal and stress-free. With grain size reduction of BT ceramics to nanoscale the creation of ferroelectric domains becomes difficult. Below the certain limited grain size [10] the polycrystals stay paraelectric even at room temperature. The grain size restriction has then a crucial influence on BT ceramics properties, i.e. decrease in $T_{\mathrm{c}}$ temperature [11]. 
Current work contains a direct process of the polycrystalline BT powders synthesis using MSS technique. The sequent part is about the material characterization. $\mathrm{X}$-ray diffraction (XRD) analysis and precise diffraction lines defining allows to calculate unit cells parameters and tetragonality factor using the Cohen method [12]. From peaks broadening there were estimated both the crystallite size and lattice strain level, according to the Williamson-Hall method (W-H) [13]. Through scanning electron microscopy (SEM) investigations of BT powders morphology the grain size distribution were measured. Dielectric studies were carried out for sintered BT ceramics to measure relative permittivity as a temperature function to find the phase transitions mean as critical temperatures $\left(T_{\mathrm{c}}\right)$. Finally, the dielectric losses were calculated.

\section{Experimental}

Stoichiometric composition of $\mathrm{Ba}\left(\mathrm{NO}_{3}\right)_{2}$ and $\mathrm{TiO}_{2}$ was mixed together with flux in molar ratio 1:20 and ground in agate mortar. Used flux system was an eutectic composition of sodium and potassium chlorides $(\mathrm{NaCl}-\mathrm{KCl}$, molar ratio 50:50). This system provides an efficient diffusion of reactants and it is chemically inert with respect to them and easy to separate. Final mixture was placed into corundum crucible.

The process was carried out in resistance furnace in three independent temperature variants: 850,900 , and $100{ }^{\circ} \mathrm{C}$ with isothermal time $2 \mathrm{~h}$ for each one. After the process finished, a volumetric boule consisted of flux and dispersed particles of polycrystalline powder was obtained. The procedure of separation main product from the flux includes the chlorides dissolution in hot deionised water, cyclic sedimentation of powder suspension and examine the filtrate with $\mathrm{gNO}_{3}$ for detection and remove residual chlorides and finally drying the powder specimen. The sample is ready for further studies.

\section{Results and discussion}

The XRD powder diffraction analysis was made using Bruker D8 Discover diffractometer with $\mathrm{Cu} K_{\alpha} \lambda=$ $1.54058 \AA$ and step size $0.017113^{\circ}$. The diffraction patterns are shown in Fig. 1.

XRD studies revealed that it is possible to obtain perovskite phase even at $850^{\circ} \mathrm{C}$. Indeed, current pattern contains a few low-intense additive peaks (in $2 \theta$ range of $22-30^{\circ}$ and $35-45^{\circ}$ ), probably corresponding to residual unprocessed substrates. Nevertheless their quantity and quality share is insignificant. For synthesis in temperatures $900^{\circ} \mathrm{C}$ and $1000^{\circ} \mathrm{C}$, respectively, high-purity phases were obtained. In each case it was compatible with tetragonal perovskite structure pattern. The peaks starting from (200) are split clearly, the most distinctly for $1000{ }^{\circ} \mathrm{C}$, for the rest they are partially overlapping.

To determine precise unit cell parameters the Cohen method was used, according to previous data from X-ray

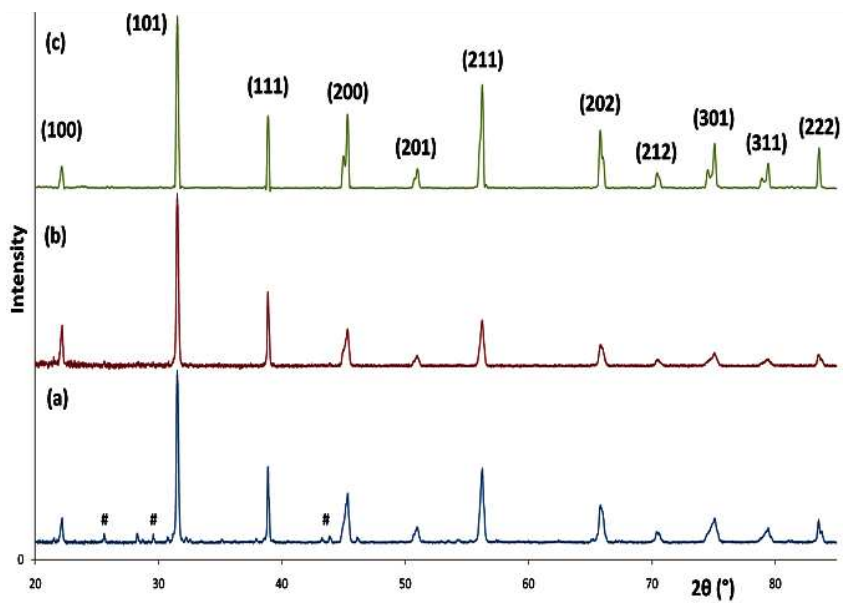

Fig. 1. Diffraction patterns of BT powders obtained in MSS at temperatures $850{ }^{\circ} \mathrm{C}(\mathrm{a}), 900^{\circ} \mathrm{C}(\mathrm{b}), 1000^{\circ} \mathrm{C}(\mathrm{c})$.

diffraction. This method is derived from Bragg's law and it is integral for all diffraction lines in the pattern. Calculation results are attached in Table I. It was noticed that there is no considerable differences in lattice parameters and tetragonality factor for BT samples prepared at indicated temperatures. The ratios $c_{0} / a_{0}$ are comparable to theoretical value (1.011). It indicates on tetragonal phase structure.

TABLE I

Calculating lattice constants of synthesized BT powders.

\begin{tabular}{|c|c|c|c|}
\hline $\begin{array}{l}\text { Sample } \\
\text { id. }\end{array}$ & $\begin{array}{c}\text { Process } \\
\text { temperature }\end{array}$ & Parameters & $c_{0} / a_{0}$ \\
\hline (a) & $850^{\circ} \mathrm{C}$ & $\begin{array}{l}c_{0}=4.0258 \pm 0.0023 \AA \\
a_{0}=3.9948 \pm 0.0022 \AA\end{array}$ & 1.0078 \\
\hline (b) & $900^{\circ} \mathrm{C}$ & $\begin{array}{l}c_{0}=4.0264 \pm 0.0023 \AA \\
a_{0}=3.9927 \pm 0.0022 \AA\end{array}$ & 1.0084 \\
\hline (c) & $1000^{\circ} \mathrm{C}$ & $\begin{array}{l}c_{0}=4.0225 \pm 0.0023 \AA \\
a_{0}=3.9927 \pm 0.0022 \AA\end{array}$ & 1.0075 \\
\hline Ref. [14] & & $\begin{array}{l}c_{0}=4.036 \AA \\
a_{0}=3.992 \AA\end{array}$ & 1.011 \\
\hline
\end{tabular}

Crystallite size and lattice strain were investigated via the Williamson-Hall method. The Bragg positions was described using the Pearson VII distribution [15]. The Pearson VII is a compromise in general case when profile related with crystallite size is specified with Cauchy's function, while profile corresponding to lattice strain is described with Gaussian function. Calculated peaks parameters were then differentiated with respect to standard reference material of lanthanum hexaboride (SRM 660a). Both for SRM and BT peaks there was used the full width at half maximum (FWHM) [16] as broadening line measure. The Williamson-Hall plots were drawn below in Fig. 2, and the examined formula is given as follows: 


$$
\left(\frac{\beta}{\tan \theta}\right)^{2}=\frac{K \lambda}{D}\left(\frac{\beta}{\tan \theta \sin \theta}\right)+16 e^{2},
$$

where

$$
\beta=B\left(1-\frac{b^{2}}{B^{2}}\right)
$$

( $b$ is for SRM 660a FWHM and $B$ stands for diffraction lines FWHM), $\theta$ - Bragg's angle, $\lambda$ - source wavelength, $D$ - average crystallite size, $e$ - lattice strain and $K=0.89$ is a constant value in given formula. Both profile fitting and error analysis were done using similar method described in [17].

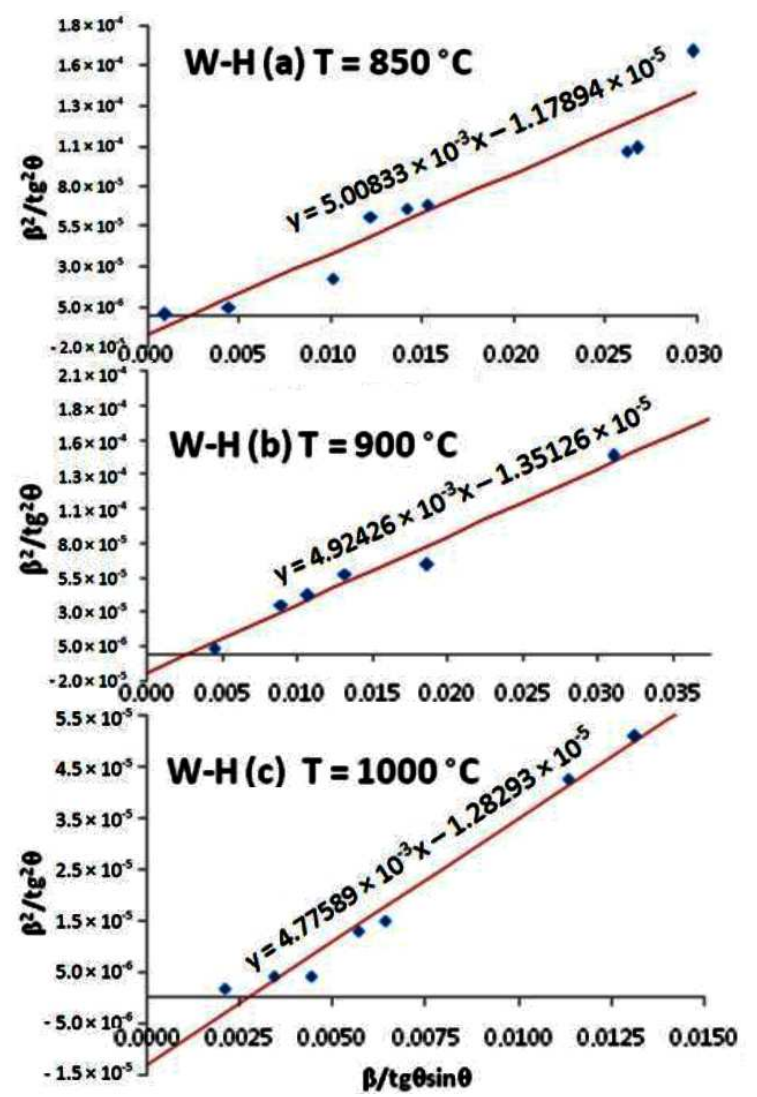

Fig. 2. Williamson-Hall plots for obtained BT samples with linear fitting and regression coefficients.

Average crystallite size and relative value of lattice strain were determined from linear fit coefficients. Final results were given in Table II. It was found that with increase in temperature the crystallite size grows, while structure deformation is not dependent on temperature and its values are comparable and so low (the order of $0.01 \%$ ) that they do not affect the properties of fabricated ceramics. Negative values of coefficient referred to lattice strain are due to fact that the deformations in microstructure were compressive. It is explained as the excess of flux at the end of synthesis interacts with inert BT particles which are trapped in medium and counteract with changes of its geometry. Thermal expansion coefficients of these compounds are different so that agent participates in this effect.

TABLE II

Average crystallite sizes and lattice strain of obtained BT powders.

\begin{tabular}{c|c|c|c}
\hline \hline $\begin{array}{c}\text { Sample } \\
\text { id. }\end{array}$ & $\begin{array}{c}\text { Process } \\
\text { temperature }\end{array}$ & $\begin{array}{c}\text { Crystallite } \\
\text { size }\end{array}$ & Lattice strain \\
\hline (a) & $850^{\circ} \mathrm{C}$ & $27 \pm 4 \mathrm{~nm}$ & $0.086 \pm 0.082 \%$ \\
(b) & $900^{\circ} \mathrm{C}$ & $28 \pm 3 \mathrm{~nm}$ & $0.092 \pm 0.066 \%$ \\
(c) & $1000^{\circ} \mathrm{C}$ & $29 \pm 3 \mathrm{~nm}$ & $0.090 \pm 0.039 \%$
\end{tabular}

To estimate crystallite size a type of diffraction method was applied. It is not a direct technique and not based on observation of any individual crystallites or particles, so the results are only estimated. The reliability of this method is a frequent and questionable subject of its own pioneers [18].

The microstructural studies were undertaken using Scanning Electron Microscope Quanta 3D FEG Dual Beam. For showed SEM photos (Fig. 3) it is difficult to determine the unequivocal shape and size of single grain. Fields of vision are dominated with pseudospherical grains, an elongated agglomerated rods are also visible and irregular, two-dimensional layers, too. Agglomeration is strongly dependent on process temperature, as well as sample preparation. The grain size is increasing in temperature.

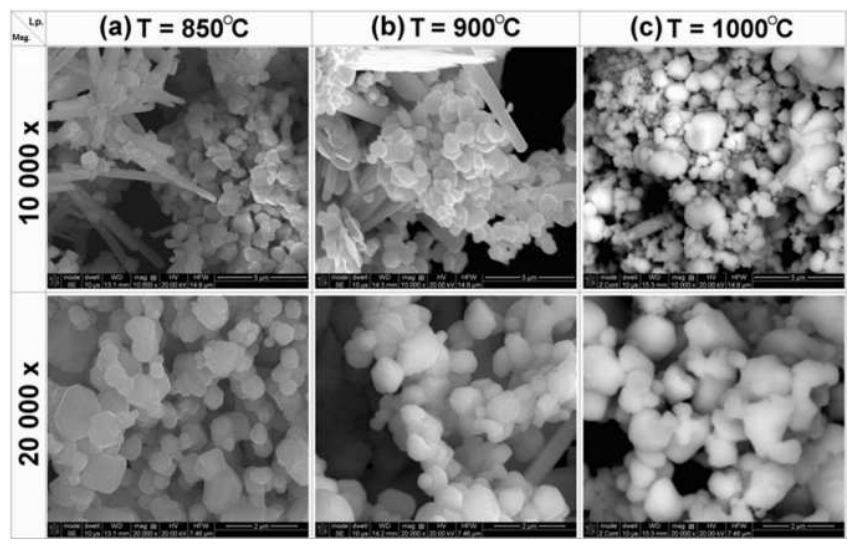

Fig. 3. SEM photos of BT powders.

From several fields all distinct grain sizes were collected and grain size distribution for each synthesis variant was done. Equivalent circular diameter (ECD) is a measure of the probability density for appearance of grain with particular size provided it is ideally spherical. ECD plot is shown in Fig. 4. Increasing in temperature the distribution curve becomes broadened and flattened, and it means that probability of finding larger grain grows. The curve is then shifted towards the micron range. The ECD of spherical grain grows with increasing in process temperature from 550 to $700 \mathrm{~nm}$ and remains in sub-micron range. 


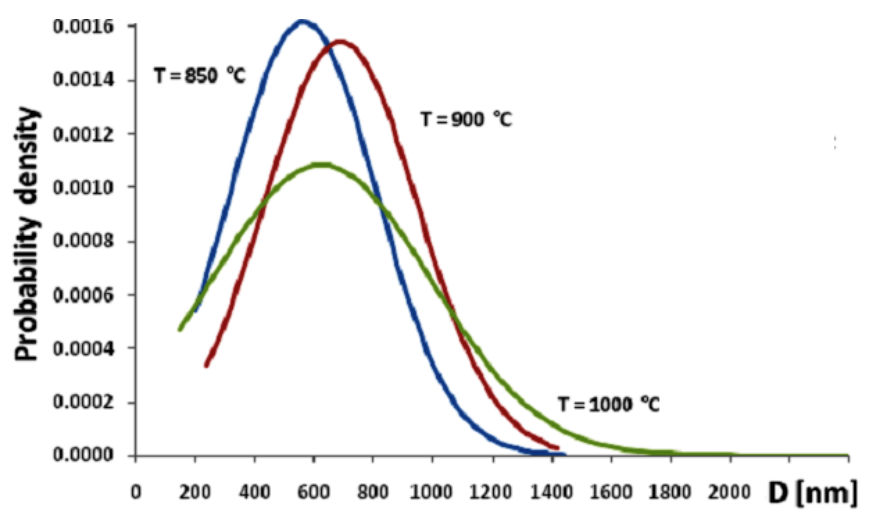

Fig. 4. ECD grain size distribution for BT powders.

Dielectric measurement required convert powders into bulk samples. They all were pressed using OTTO Wwe$200 \mathrm{~T}$ hydraulic press with $500 \mathrm{MPa}$ pressure held for $1 \mathrm{~min}$ giving $20 \mathrm{~mm}$ discs, which were sintered in electric furnace Elterma PSK- 7 at $1250^{\circ} \mathrm{C}$ for $4 \mathrm{~h}$ getting compact and dense elements. Surfaces of each sample were bilaterally covered with silver paste acting as electrodes and all sinters were thermally stabilized. Electrodes and conductors were soldered together. The as-prepared capacitors were included into circuit and the measurements were done using HP 4192 LF Impedance nalyzer with $1 \mathrm{~V}$ voltage and $100 \mathrm{~Hz}-1 \mathrm{MHz}$ frequency range. The relative permittivity characteristics are given in Fig. 5 .

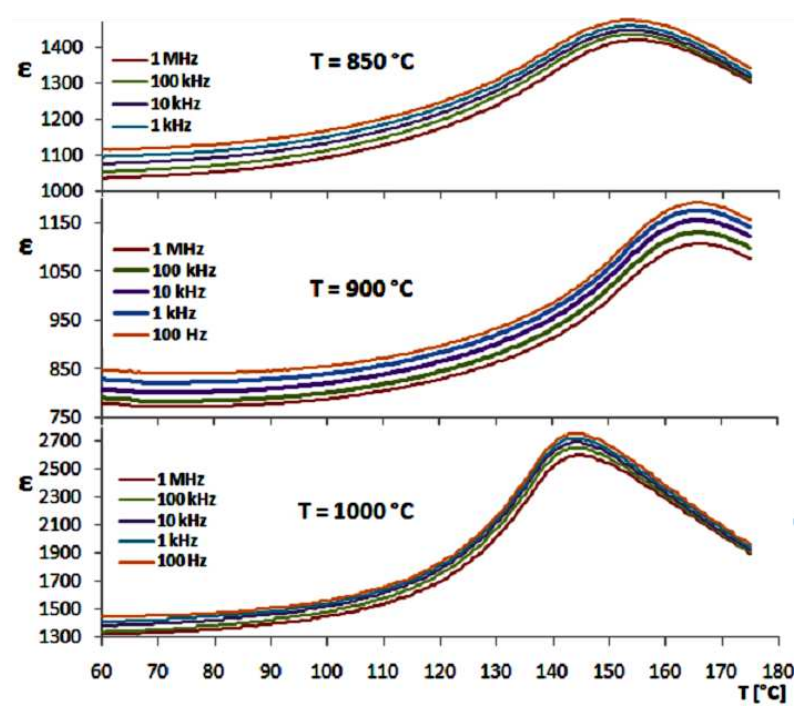

Fig. 5. Relative permittivity versus temperature for sintered BT capacitors.

The results are divergent. The highest value of electric permittivity was found for the specimen synthesized at $100{ }^{\circ} \mathrm{C}$, for which the largest grains share in microstructure was indicated, too. The phase transition is the clearest and the most similar to theory $\left(T_{\mathrm{c}}=135^{\circ} \mathrm{C}\right)$ also in this case. For the rest it is slightly distorted and shifted towards higher temperature, because of inhomogeneity on microstructural level. The critical temperature for samples processed at $850{ }^{\circ} \mathrm{C}, 900^{\circ} \mathrm{C}$, and $1000^{\circ} \mathrm{C}$ is equal to $155^{\circ} \mathrm{C}, 166^{\circ} \mathrm{C}$, and $144^{\circ} \mathrm{C}$, respectively. Besides of permittivity the dielectric loss factor was measured too, as a function of electric field frequency. The plot is shown in Fig. 6.

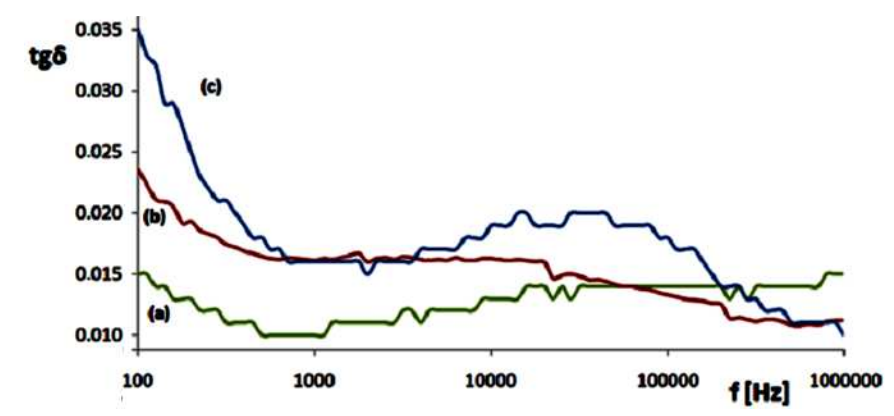

Fig. 6. Dielectric loss factor versus frequency for samples prepared at temperatures $850{ }^{\circ} \mathrm{C}$ (a), $900{ }^{\circ} \mathrm{C}$ (b), $1000{ }^{\circ} \mathrm{C}(\mathrm{c})$.

The measurement did not reveal considerable differences for ceramics obtained at each temperature. The dielectric loss is comparable with values founded for the same material but fabricated through conventional routes and they are equal to about $1-3 \%$ for frequency $1 \mathrm{kHz}$ at lowest temperature of single measurement $\left(T=60^{\circ} \mathrm{C}\right)$. Typically, the loss changes are the most dependent on capacitor work temperature and maximal reached values of permittivity.

\section{Conclusions}

Tetragonal phase of $\mathrm{BaTiO}_{3}$ was achieved through MSS method at temperature $850^{\circ} \mathrm{C}$ in process time $2 \mathrm{~h}$. The presence of tetragonal system was confirmed by experimentally calculated unit cell parameters. The tetragonality factor is not strongly dependent on the process temperature in range $850-1000^{\circ} \mathrm{C}$. The estimated crystallite sizes under indicated conditions are similar to themselves. Agglomeration of particles in powders microstructure is highly dependent on temperature and MSS route leads to formation of pseudospherical particles with submicron sizes. Dielectric measurements indicated particular influence of particle size and temperature on electric permittivity values and on the differences between phase transition points. The considerable differences of dielectric loss for obtained ceramics were not found.

\section{References}

[1] W. Chen, S. Kume, K. Watari, Mater. Lett. 59, 3238 (2005).

[2] T.X. Wang, S.Z. Liu, J. Chen, Powder Technol. 205 , 289 (2010). 
[3] F. Bortolani, R.A. Dorey, J. Europ. Ceram. Soc. 30, 2073 (2010).

[4] G.K. Sahoo, Synthesis and Characterization of $\mathrm{BaTiO}_{3}$ Prepared by Molten Salt Synthesis Method, Department of Ceramic Engineering N.I.T. Rourkela - 769 008, 2009

[5] H. Liu, L. Guo, L. Zou, M. Cao, J. Zhou, S. Ouyang, Mater. Sci. Eng. B-Solid State Mater. Adv. Technol. 113, 161 (2004).

[6] J. Główczyk-Zubek, A. Gabrylewicz, Titanium Dioxide - Properties and Aplications in Cosmetics, Wydział Chemiczny Politechniki Warszawskiej, Warszawa 2007 (in Polish).

[7] J.P. Remeika, W. Morrison Jackson, J. Am. Chem. Soc. 76, 940 (1954).

[8] M.H. Garrett, I. Mnushkina, J. Cryst. Growth $\mathbf{1 6 6}$ 550 (1996).

[9] M.H. Frey, D.A. Payne, Phys. Rev. B 54, 3158 (1996).

[10] C. Pakokthom, G. Rujijanagul, T. Tunkasiri, J. Mater. Sci. Lett. 18, 747 (1999).
[11] J. Zhu, C. Jin, W. Cao, X. Wang, Appl. Phys. Lett. 92, 242901 (2008).

[12] M.U. Cohen, Rev. Sci. Instrum. 6, 68 (1935).

[13] G.K. Williamson, W.H. Hall, Acta Metall. 1, 22 (1953).

[14] Y. Jung, D. Lim, J. Nho, S. Cho, R.E. Riman, B.W. Lee, J. Cryst. Growth 274, 638 (2005).

[15] P.S. Prevéy, Adv. X-ray Anal. 29, 103 (1986).

[16] M. Meier, Measuring Crystallite Size Using X-ray Diffraction, The Williamson-Hall Technique (Draft), Department of Chemical Engineering and Materials Science, University of California, Davis, US 2005.

[17] V.D. Mote, Y. Purushotham, B.N. Dole, J. Theor Appl. Phys. 6, 6 (2012).

[18] E.J. Mittemeijer, U. Welzel, Z. Kristall. 223, 552 (2008). 